\title{
Assessment of atrioventricular septal defects by two dimensional echocardiography
}

\author{
J F SMALLHORN, G TOMMASINI^, R H ANDERSON, F J MACARTNEY \\ From The Hospital for Sick Children, Great Ormond Street, and the Cardiothoracic Institute, Brompton Hospital, \\ Fulham Road, London
}

SUMMARY Ninety-six patients with an atrioventricular septal defect were assessed by two dimensional echocardiography. Forty-eight patients were judged as having two discrete valve orifices. In this group, 37 had an intact ventricular septum and 11 a ventricular septal defect. Two patterns of attachment of the valve leaflets to the interventricular septum were noted. Forty-eight patients had a common valve orifice. In 29 patients there was absence of tethering of the anterior bridging leaflet to the interventricular septum. A further 19 had varying degrees of tethering of the anterior bridging leaflet. A ventricular septal defect was identified under the anterior bridging leaflet in all cases. In 58 cases where the posterior bridging leaflet was identified, a ventricular septal defect was visualised in eight and missed in two.

Seventy-eight patients had an ostium primum defect, 12 a common atrium, and a further six an intact interatrial septum. Two dimensional echocardiography provides in depth morphological information about the type of atrioventricular defect and can correctly identify the presence of a ventricular septal defect beneath the anterior or posterior bridging leaflet, unless it exists between short crowded chordae.

The assessment of the atrioventricular junction is readily achieved by two dimensional echocardiography. Since atrioventricular septal defects are primarily an abnormality of this region, reliable delineation of their detailed morphology should be possible by this technique. Indeed, Hagler et al. ${ }^{1}$ showed that, using echocardiography, it was possible to identify with reasonable accuracy "partial" atrioventricular septal defects, together with the three varieties of "complete" defect described by Rastelli et al. ${ }^{2}$

The Rastelli classification has the great merit of simplicity, and has for many years been used for reporting surgical results. More recently its value in this respect has been questioned. ${ }^{3}$ Furthermore, it describes only one aspect of atrioventricular septal defects, being based on the morphology of the anterior bridging leaflet, and does not allow for description of the so-called "transitional forms" which undoubtedly exist in addition to the "partial" and "complete" varieties. ${ }^{4}$ Full description of an atrioventricular septal defect depends on identifying

^Present address: Divisione di Cardiochirurgia Infantile, Ospedale Civile, Massa, Italy.

Accepted for publication 30 September 1981 all abnormalities of the valve orifice, valve leaflet tissue, and tension apparatus, in addition to describing the interatrial and interventricular communications if present. ${ }^{56}$ Associated abnormalities are then tabulated. This study was carried out in order to see whether two dimensional echocardiography could reliably describe all these anatomically observed features of atrioventricular defects, thus permitting descriptive rather than procrustean categorisation.

\section{Subjects and methods}

Ninety-six cases of atrioventricular septal defect were examined routinely during a 12 month period at The Hospital for Sick Children, Great Ormond Street. Patients with univentricular hearts and common atrioventricular orifice were excluded, these having been described elsewhere. ${ }^{7}$ In the majority the diagnosis was unknown at the time of examination, but in some, cardiac catheterisation and angiocardiography had previously been performed.

The children were examined using an Advanced Technology Laboratory Mechanical Sector Scanner, with a 3.0 or $5 \mathrm{MHz}$ transducer. Both the apical and subcostal four chamber views were used. The former 
approach visualised most clearly the more anterior (Fig. 1), and the latter the more posterior part of the interventricular septum (Fig. 2).

The presence of an interventricular communication beneath the posterior bridging leaflet was determined, firstly from a subcostal four chamber cut and then by clockwise rotation of the transducer into the long axis. In the former cut the posterior bridging leaflet could be seen (Fig. 2). With clockwise rotation of the transducer the anterior leaflet and its attachment to the left ventricular outflow tract was visualised. In addition, the posterior bridging leaflet could be seen in this cut (Fig. 3) and during real-time assessment its chordal attachments to the septum were noted.

Presence or absence of an interventricular communication beneath the anterior bridging leaflet could best be assessed in the apical four chamber view. The insertions of the anterior bridging leaflet within the right and left ventricles were also determined in this cut. The extent and integrity of the interatrial septum and the presence of associated defects were assessed by combining standard views as previously described. ${ }^{8}$

The anatomy observed is described using the nomenclature proposed by Piccoli et al. ${ }^{5} 6$ The criteria used for angiocardiographic analysis, and specifically those differentiating defects beneath the anterior and posterior bridging leaflets, were those indicated by Macartney et al. ${ }^{9}$

\section{Results}

ATRIOVENTRICULAR SEPTAL DEFECTS WITH SEPARATE VALVE ORIFICES

Forty-eight patients had two discrete atrioventricular orifices as assessed by two dimensional echocardiography. In 37 of these the bridging leaflets and the connecting tongue between them were firmly attached to the crest of the ventricular septum so that no interventricular communication was present. Two patterns of attachment of the bridging leaflets and connecting tongue to the septum were identified.

In 20 the anterior bridging leaflet was itself turned in and firmly adherent to the crest of the septum along its length (Fig. 4). In 17 further cases the anterior interventricular component was blocked by longer, but tightly packed or fused chordae between the bridging leaflet and the crest. In six of these the chor-
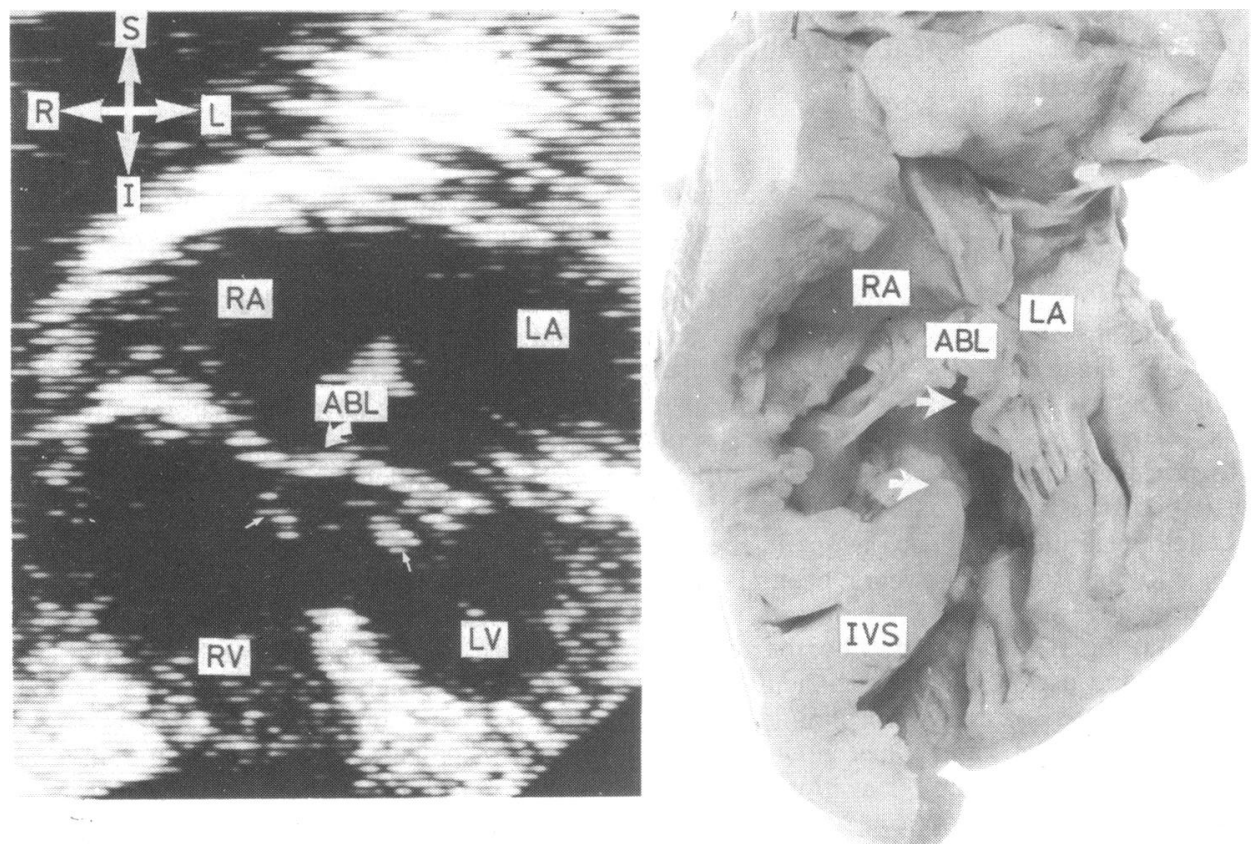

Fig. 1 The left hand panel is an apical four chamber cut in a case with a common atrioventricular orifice and a free floating anterior bridging leaflet. Note the absence of chordal attachments to the interventricular septum. The small arrows point to the chordal attachments of the leaflet. The right hand panel is a specimen with a common atrioventricular orifice, illustrating the echocardiographic features on the left. The white arrows indicate the ventricular septal defect. $A B L$, anterior bridging leaflet; $I V S$, interventricular septum; LA, left atrium; LV, left ventricle; $R A$, right atrium; $R V$, right ventricle. 

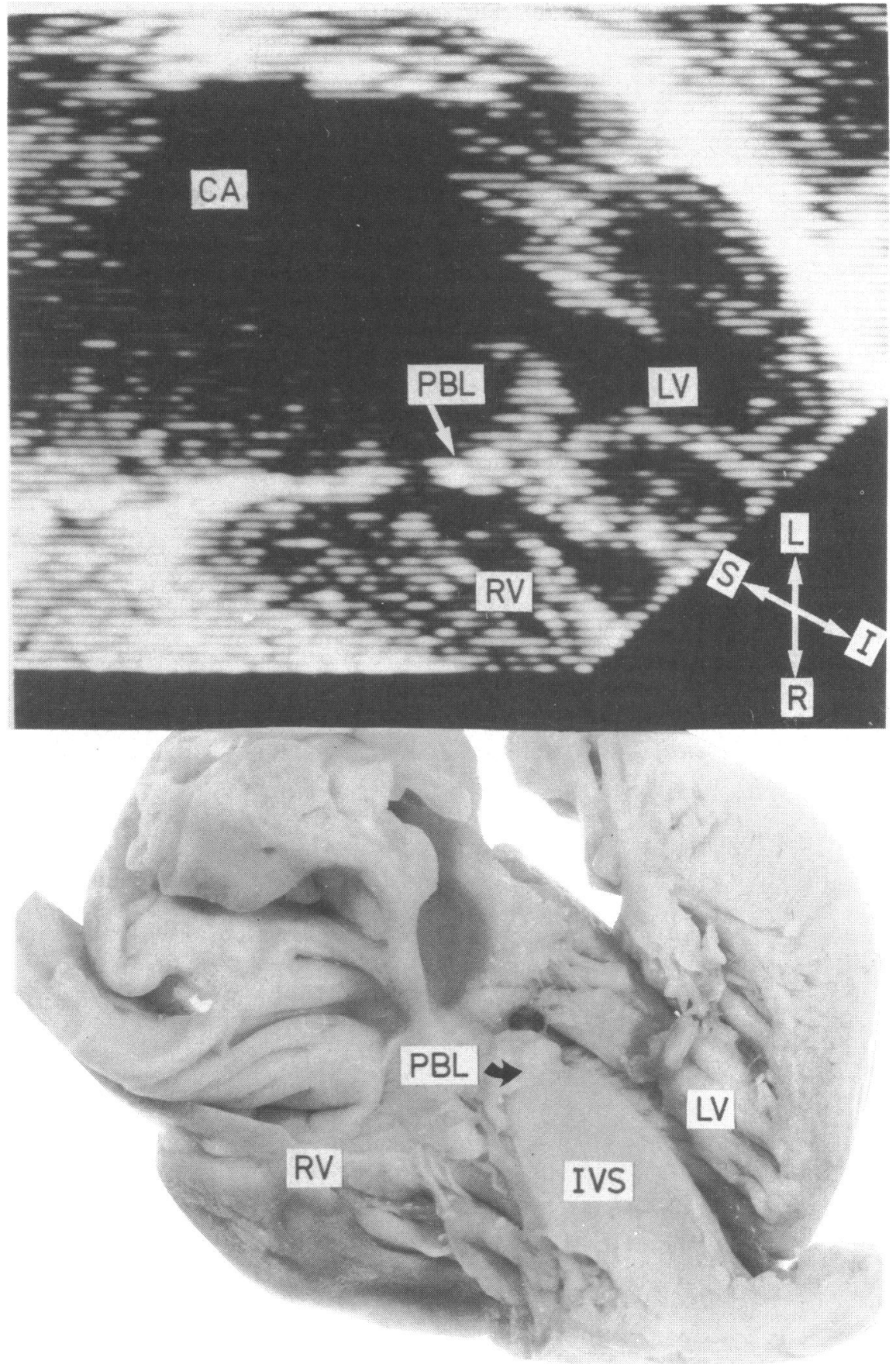

Fig. 2 The upper panel is a subcostal four chamber cut, with the transducer angled posteriorly. The attachment of the posterior bridging leaflet at the crux of the heart can be seen. The lower panel is a different anatomical specimen showing the posterior bridging leaflet attached at the crux of the heart. Note, here the septum secundum is present. CA, common atrium; $P B L$, posterior bridging leaflet. See Fig. 1 for remaining abbreviations. 

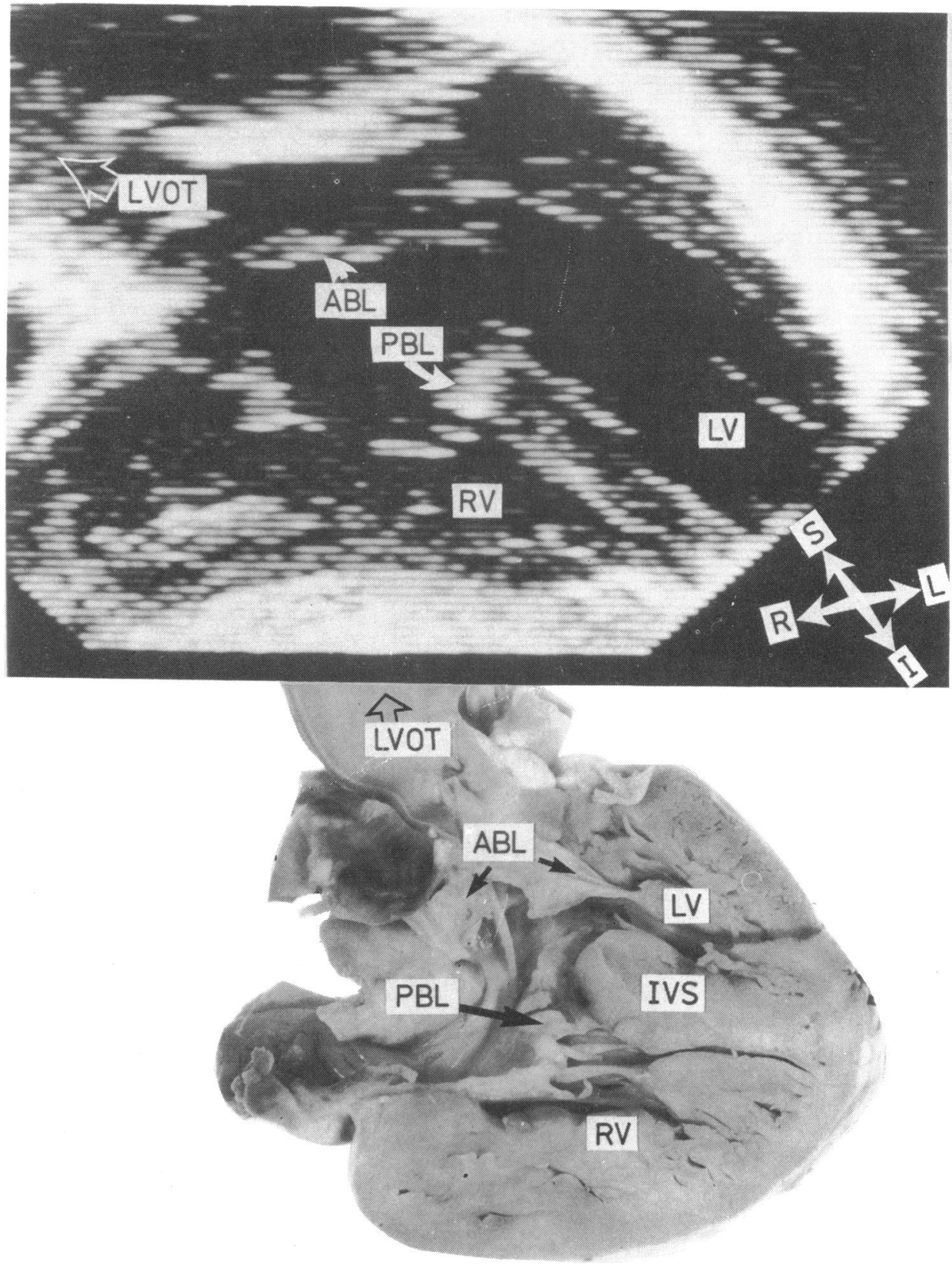

Fig. 3 The upper panel is a subcostal long axis cut showing the anterior and posterior bridging leaflets. Note the posterior bridging leaflet is attached to the posterior part of the interventricular septum and the anterior bridging leaflet to the left ventricular oufflow tract. The lower panel is a specimen cut in a long axis view to show the attachments of the anterior and posterior bridging leaflets. LVOT, left ventricular outflow tract. See Fig. 1 for remaining abbreviations. 
dae inserted onto the septal crest, while in 11 they inserted immediately to the right of the septal crest (Fig. 5). Even during real-time examination, no defects could be seen under the anterior bridging leaflet of these patients. In this group, confirmation of the lesion was possible in 35 patients at either cardiac catheterisation, surgery, and/or necropsy.

In 11 cases, a communication was found between the valve leaflets and the septal crest. All had associated "clefts" in the left sided atrioventricular valve and in two cases surgical confirmation of an atrioventricular defect was possible. In five the atrioventricular valves appeared to be attached to a structure in between the interatrial and interventricular communications (Fig. 6).

Of the cases with two separate atrioventricular orifices, six had an intact atrial septum as judged echocardiographically (Table 1), the lower edge of the septum extending down to the closure plane of the atrioventricular valve leaflets. At operation one of these patients had a very small anterior interatrial defect plugged by the anterior bridging leaflet. In two further cases the lower edge of the atrial septum
Table 1

\begin{tabular}{lll}
\hline & $\begin{array}{l}\text { AV defects with } \\
\text { separate orifices } \\
(\text { No. 48) }\end{array}$ & $\begin{array}{l}\text { AV defects with a } \\
\text { common orifice } \\
\text { (No. 48) }\end{array}$ \\
\hline $\begin{array}{l}\text { Ostium primum } \\
\begin{array}{l}\text { Intact atrial septum } \\
\text { Common atrium }\end{array}\end{array}$ & $\begin{array}{c}39(81 \%) \\
6(13 \%)\end{array}$ & $39(81 \%)$ \\
\hline
\end{tabular}

extended almost to the level of the atrioventricular valves but was slightly displaced to the left. During invasive investigation the catheter appeared to pass directly from the right atrium to the left ventricle, and in one of these the left atrium could not be entered. Thirty-seven cases had a more generous and typical ostium primum atrial septal defect, while in the final three there was a common atrium (Figs. 4 and 6).

ATRIOVENTRICULAR SEPTAL DEFECTS WITH COMMON ATRIOVENTRICULAR ORIFICE

Forty-eight patients were judged to have nonpartitioned orifices by two dimensional echocardiography. In 29 cases there was absence of tethering of

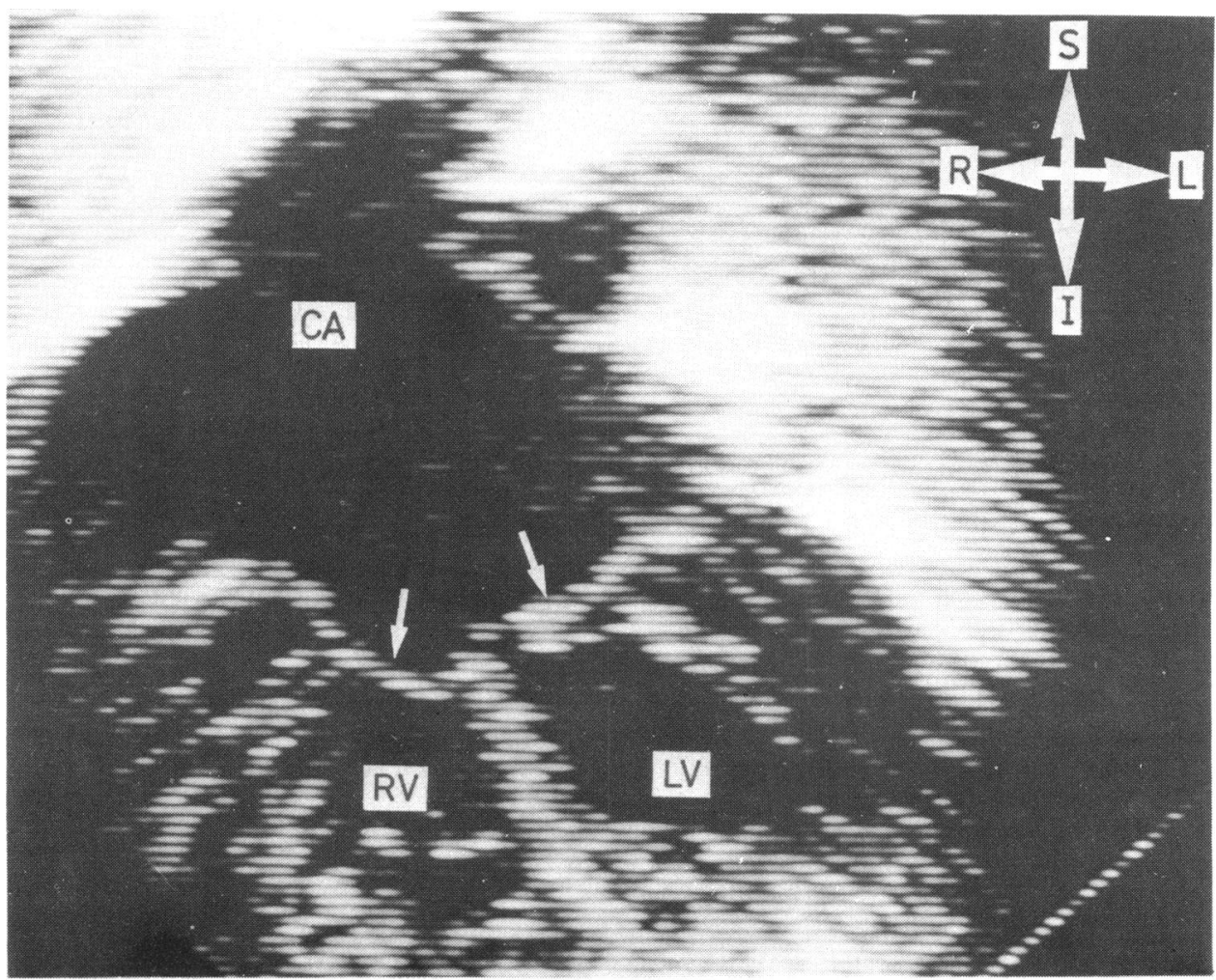

Fig. 4 An apical four chamber cut in a case with partitioned orifices and no ventricular component. Note that the left and right sided atrioventricular leaflets, indicated by the arrows, are firmly adherent to the interventricular septum. See Figs. 1 and 3 for abbreviations. 


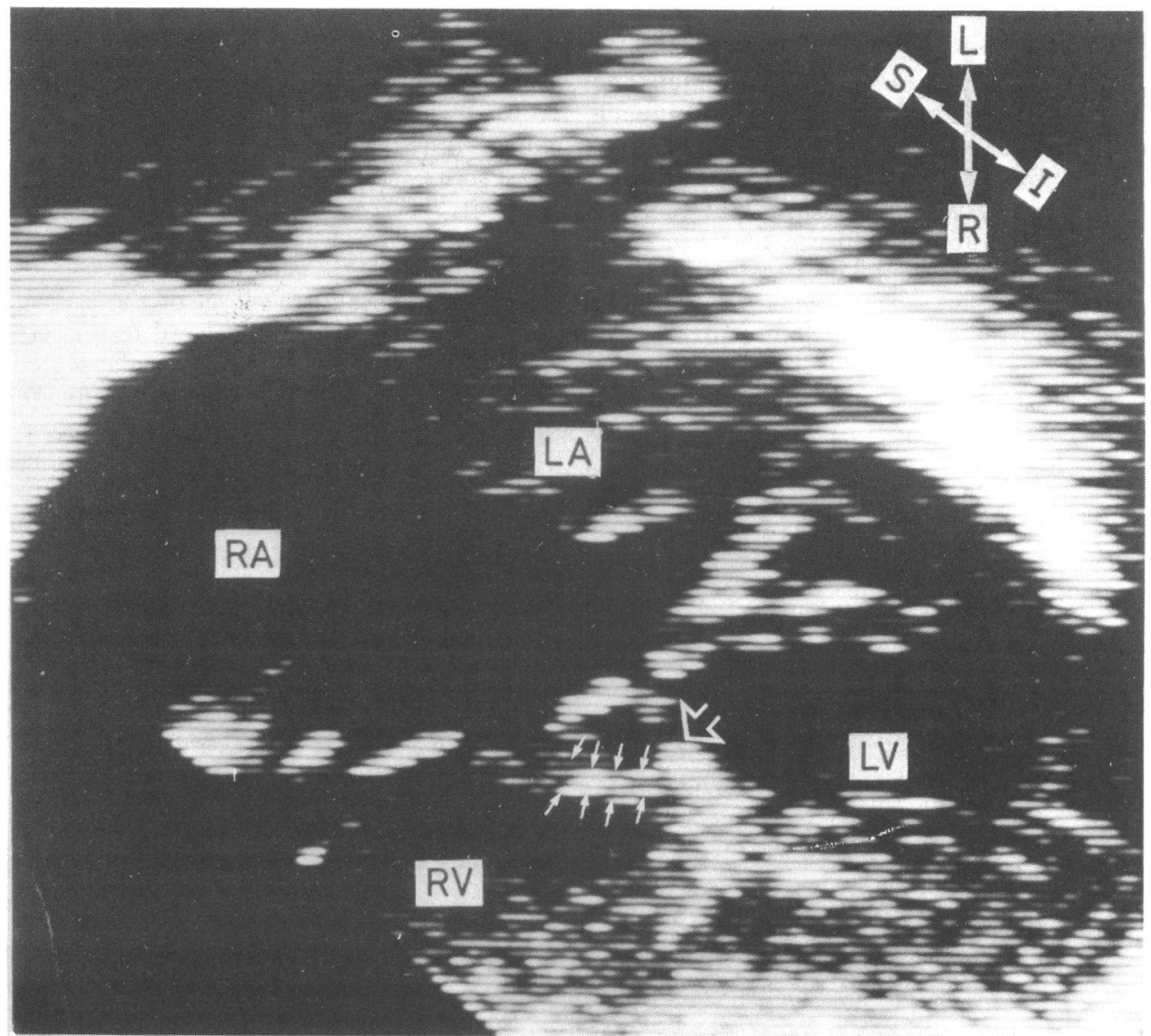

Fig. 5 An apical four chamber cut in a case with partitioned orifices and no ventricular component. Note that the chordae, indicated by small arrows, are inserted into the right side of the interventricular septum. The large open arrow points to the crest of the interventricular septum. See Fig. 1 for abbreviations.

the anterior bridging leaflet to the interventricular septum (Fig. 1). Nine patients had long thin chordae, tethering the anterior bridging leaflet to the crest of the interventricular septum so as to divide it into equal parts (Fig. 7). In five the chordae from the anterior leaflet were tethered to the right side of the crest of the septum (Fig. 8), with the papillary muscle insertion being at its base. Five others had the same papillary muscle insertion, but no chordae tethering the anterior leaflet were seen.

An interventricular communication was seen in all patients beneath the anterior bridging leaflet in the apical four chamber view. Surgical, necropsy, or angiocardiographic confirmation of this finding was available in 37 patients.

In 41 patients in whom the posterior septum was clearly visualised and independent confirmation of the diagnosis was available, an interventricular defect beneath the posterior bridging leaflet was correctly diagnosed in four patients and missed in two (Fig. 9). Absence of such a defect was correctly diagnosed in the other 35 patients. In a further group of 17 patients without other confirmatory evidence, a posterioro defect was visualised in three and was absent in the remainder.

INTEGRITY OF ATRIAL SEPTUM

Nine patients with a common atrioventricular orificeN had a common atrium and 39 had an ostium primum defect of varying size (Table 1). In no case did the 0 interatrial septum extend to the level of the atrioventricular annulus.

PAPILLARY MUSCLES AND MITRAL "CLEFTS"

In all cases, regardless of whether the atrioventricular $\overline{0}$ orifice was partitioned or not, two papillary muscles in the left ventricle were identified in the short axis view. A "cleft" in the left sided atrioventricular valve was 


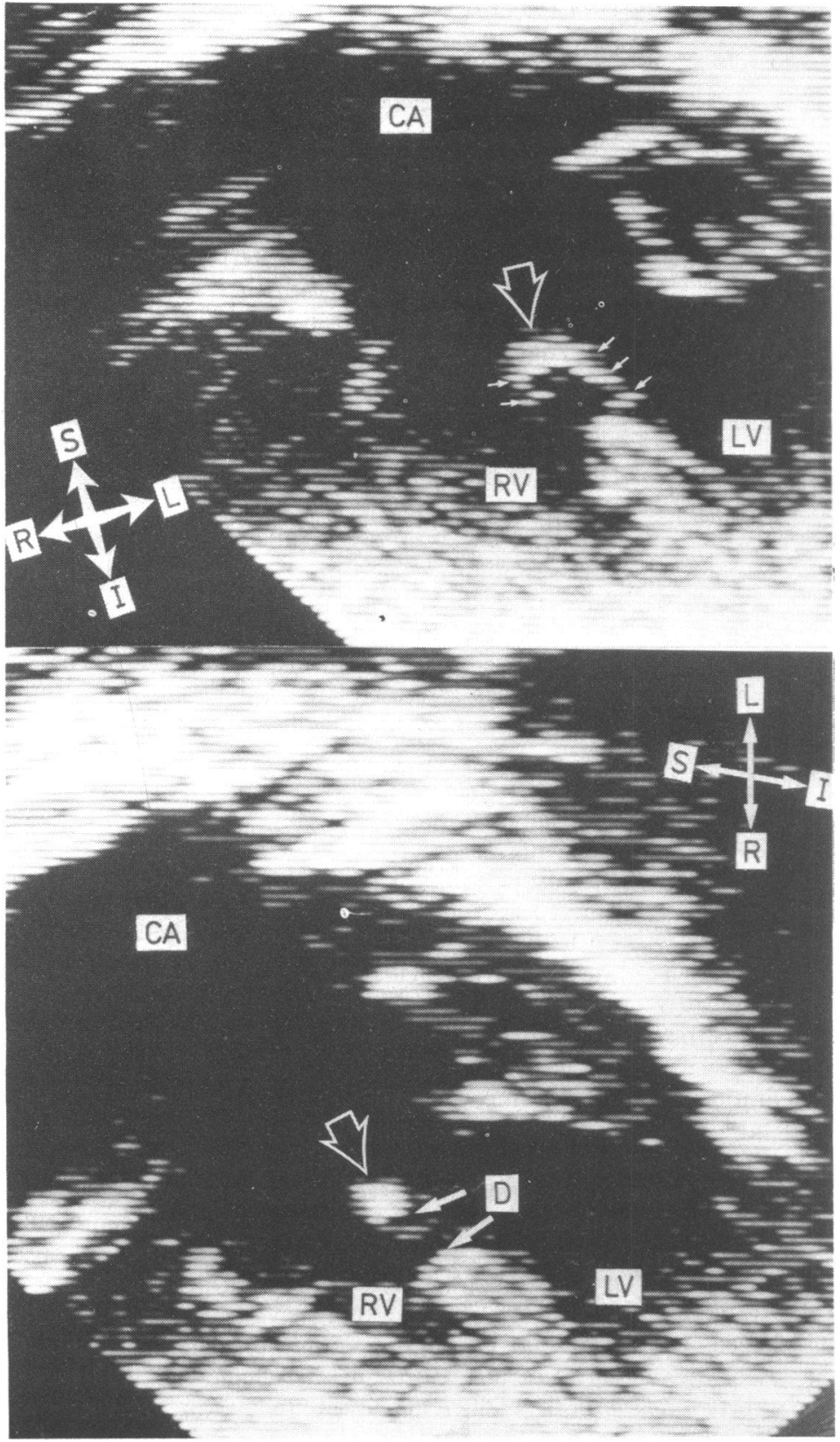

Fig. 6 The upper picture is an apical four chamber cut in a case with partitioned orifices and a ventricular component. The small arrows indicate the medial components of the right and lefi sided atrioventricular leaflets. The lower picture shows the ventricular component indicated by arrows. A dense echo (hollow arrow) between the atrium and the tip of the interventricular septum represents a strand of tissue joining the anterior and posterior bridging leaflets. $D$, defect. See Figs. 1 and 2 for remaining abbreviations.

seen in all cases pointing towards the interventricular septum. One patient had an additional "true" cleft in the anterior bridging leaflet which was confirmed at operation.

ASSOCIATED ABNORMALITIES IN ENTIRE GROUP OF PATIENTS

In 90 patients the atrioventricular junction was judged to be of balanced type. ${ }^{10}$ Three cases had a dominant left and three a dominant right ventricle (Table 2) (Fig. 10). The arterial connections were concordant in 83 , discordant in six, double outlet right ventricle in three, and single outlet aorta from the left ventricle in four (Table 2). Four cases had valvular pulmonary stenosis, four had pulmonary atresia, and a further two had both infundibular and valvular pulmonary stenosis.

In one patient a discrete subaortic membrane was 
Table 2 Associated defects in whole group

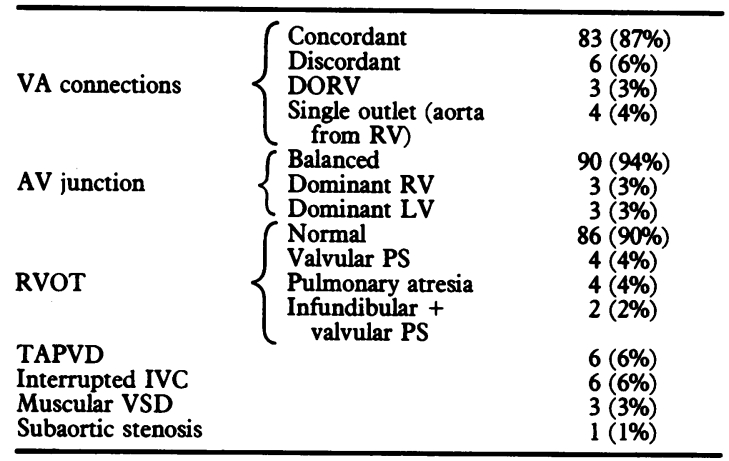

AV, atrioventricular; DORV, double outlet right ventricle; IVC, inferior vena cavae; LV, left venricle; PS, pulmonary stenosis; RV right ventricle; RVOT, right ventricular outflow tract; TAPVD, total anomalous pulmonary venous drainage; VA, ventriculoarterial; VSD, ventricular septal defect.

visualised before operation by two dimensional echocardiography. Six patients had associated total anomalous pulmonary venous drainage and another six had an interrupted inferior vena cava. Three cases had an associated muscular ventricular septal defect. In two there was also a defect under the anterior bridging leaflet and in the other the leaflets were firmly attached to the crest of the septum.

\section{Discussion}

Of all the regions of the heart, the atrioventricular junction is the most amenable to study by two dimensional echocardiography. It is hardly surprising, therefore, that the technique provides a most reliable means of detailed and precise definition of atrioventricular septal defects. M-mode echocardiography has been of some value in diagnosing the presence of an atrioventricular septal defect, ${ }^{11}$ particularly from the subcostal approach, but further morphological confirmation of the type of defect has been difficult and the visualisation of ventricular septal defects impossible in many cases. ${ }^{12}$ Hagler et al. ${ }^{1}$ studied a group of patients with atrioventricular defects by two dimensional echocardiography and used Rastelli's classification. They found some overlap between types $\mathrm{A}$ and $\mathrm{B}$, with type $\mathrm{C}$ having a distinct pattern. In that study, however, no attention was paid to assessing the posterior bridging leaflet.

Echocardiographically the anterior bridging leaflet is best visualised in a precordial four chamber cut (Fig. 1). In this view both the leaflet and its chordal insertions are well seen, along with any potential ventricular communication lying beneath.

The posterior bridging leaflet, on the other hand, is best viewed using the subcostal cut. In a four chamber view the crux of the heart and the attachment of the $c$ posterior bridging leaflet at this point can be seen $\overrightarrow{\vec{F}}$ (Fig. 2). The posterior bridging leaflet can be further assessed by clockwise rotation of the transducer, to a view where the left ventricle is seen in a long axis. In $\overline{\bar{N}}$ this position both the anterior and posterior bridging $\vec{\pi}$ leaflets can be seen. The anterior leaflet is seen at its 2 attachment to the left ventricular outflow tract and the $\infty$ posterior leaflet along the interventricular septum $\overrightarrow{0}$ (Fig. 3). The defect beneath the posterior bridging $\overrightarrow{\vec{H}}$ leaflet exists either between long chordae or under its free edge (Fig. 9).

The morphological hallmarks of an atrioventricular septal defect are fivefold. ${ }^{56}$ Firstly, the atrioventricular junction, instead of being pinched in between the tricuspid and mitral valves (as normally occurs), is $\overrightarrow{8}$ "sprung". ${ }^{13}$ Secondly, and as a result, the muscular atrioventricular septum is missing, causing the crest of the septum to be scooped out. Thirdly, the aortic $\vec{T}$ valve, instead of being wedged between the aortic and 8 mitral valves, sits in front of the sprung atrioventricular junction in a cottage loaf or snowman fashion. ₹ Fourthly, as a result of the last two, there is inlet/ $\vec{\bullet}$ outlet disproportion. ${ }^{14}$ Finally, because of the sprung atrioventricular junction and absence of the muscular atrioventricular septum, the morphology of the left and right atrioventricular valves cannot be compared with normal mitral and tricuspid valves. The anterosuperior "tricuspid" leaflet and left and right $\frac{\mathscr{Q}}{\varnothing}$ mural leaflets are confined to one ventricle. In con- $\varrho$ trast, the two remaining bridging leaflets extend bet- $\overrightarrow{\vec{O}}$ ween a left ventricular and right ventricular papillary 3 muscle. As such, they have a foot in both ventricles, the leaflets themselves crossing the septum, albeit sometimes only to a limited extent, and in other cases being firmly adherent to the septum at the crossing point.

This last point is particularly well illustrated by the cross-section echocardiographic appearances, since 8 there is a continuous spectrum of attachment of the 3 posterior and anterior bridging leaflets. This spec- 0 trum is illustrated for the anterior bridging leaflet in Figs. 1, 4, 7, and 8. At one end of the spectrum there is minimal bridging with the leaflet tissue firmly adherent to the septum. Next comes more bridging $O$ with firm adherence. There follows, instead of adher- N ence, attachment by chordae which are so tightly packed that any potential interventricular defect is effectively sealed. In these patients, dense echoes persist between leaflet tissue and septal crest throughout $\frac{}{D}$ systole and diastole. Then the chordae become wider $\stackrel{\oplus}{\oplus}$ spaced, so that a ventricular septal defect exists in the 0 interchordal spaces (Rastelli type A). Under these $\overrightarrow{0}$

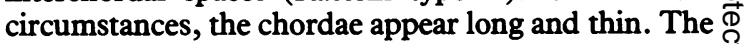
commissure thereafter moves rightward so that it is $\stackrel{\mathbb{1}}{\mathrm{D}}$ first anchored to the right side of the septum (Rastelli 


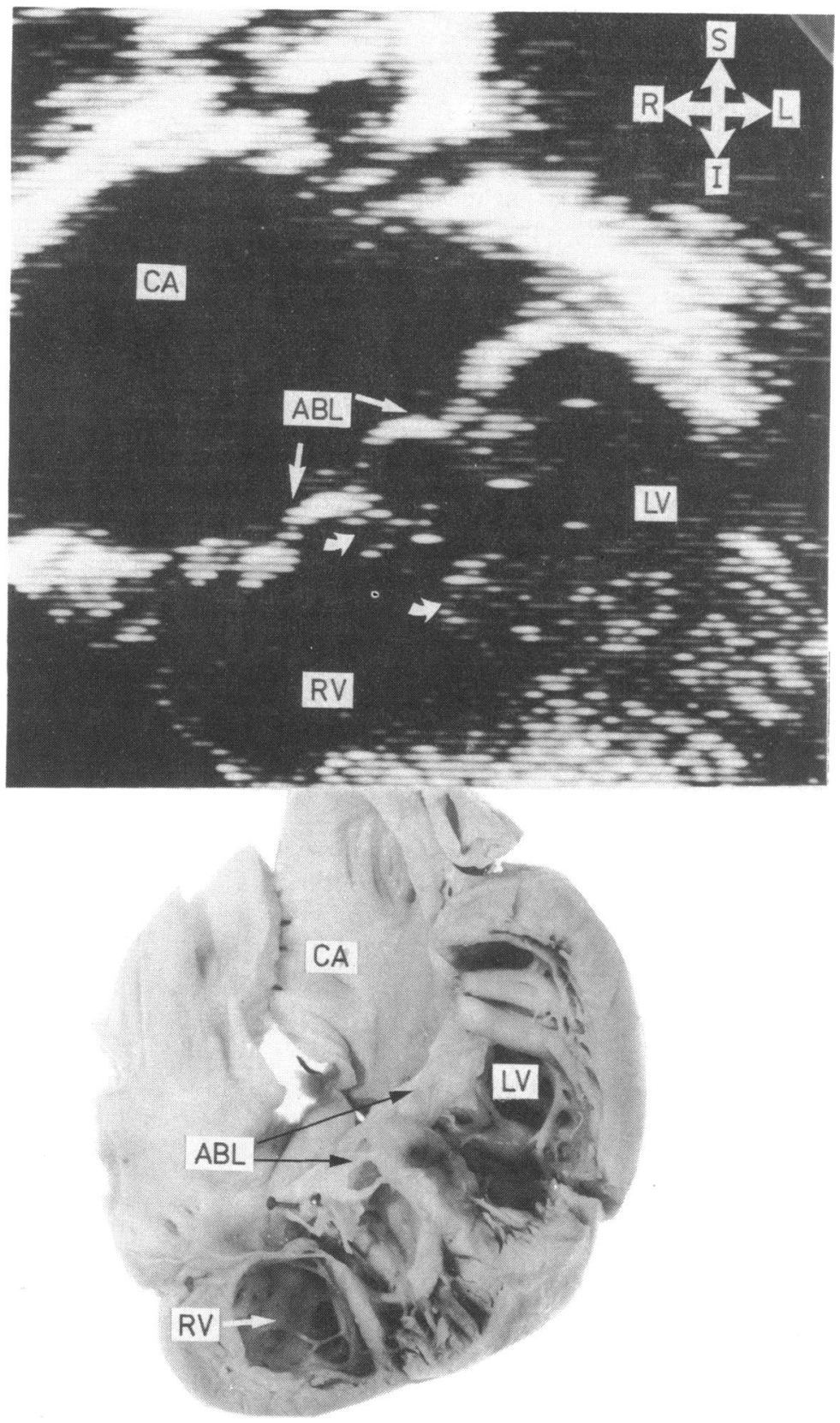

Fig. 7 The upper picture is an apical four chamber cut in a case with common atrioventricular orifice. The anterior bridging leaflet has chordae inserted into the crest of the interoentricular septum, dividing it into left and right components. The ventricular septal defect is indicated by the two arrows. The lower picture is a specimen demonstrating the chordal attachments of the anterior bridging leaflet to the interventricular septum. Note the long thin chordae tethering it to the septum. See Figs. 1 and 2 for abbreviations.

type B) and finally to the free wall of the right ventricle (Rastelli type $\mathrm{C}$ ). As the commissure has moved to the right, the anterior bridging leaflet appears to float free above the septum. Similar, but quite independent, variations in attachment of the posterior bridging leaflet occur. An additional spectrum may also be observed with respect to continuity of the anterior and posterior bridging leaflets. It is the existence of these separate spectra which has caused problems in classification of atrioventricular defects. Two quite separate traditions have existed in the past as to how to divide atrioventricular defects into complete and partial forms. In the first ${ }^{15} 16$ attention has been focused on whether there is interventricular communication between the bridging leaflets and the septal crest or not. In the second ${ }^{17} 18$ the arbiter has been 
whether or not the common atrioventricular junction is itself separated into two valve orifices. If a common atrioventricular orifice were always associated with a ventricular component beneath the bridging leaflets, and partitioned orifices were never associated with such defects, there would be no problem. The first category would be complete defects and the second would be partial defects. But this is not what is observed. The concept of transitional forms was introduced to deal with exceptions to the above rule. It has not always been appreciated, however, that two quite distinct transitional forms result. In the first, though the orifices are partitioned, there is a ventricular defect between the fused anterior and posterior bridging leaflets and the septal crest. ${ }^{16}$ Four patients showed this abnormality. An ostium primum septal defect and ventricular component were identified, separated by a strand of tissue into which the $\stackrel{\vec{c}}{.}$ atrioventricular leaflets were inserted (Fig. 8). This strand we interpret as the tongue of tissue providing $\stackrel{0}{+}$ fibrous continuity between the anterior and posterior $\frac{}{c}$ bridging leaflets. In the second, though there is no $\frac{\bar{\sigma}}{\bar{N}}$ continuity between anterior and posterior bridging $\frac{\omega}{\vec{\sigma}}$ leaflets, neither is there any defect between them and $\stackrel{\square}{\square}$ the septal crest. ${ }^{417}$ This type of transitional form might well be impossible to recognise by two $\vec{O}$ dimensional echocardiography. The anterior and posterior bridging leaflets would be seen to adhere $\vec{\omega}$

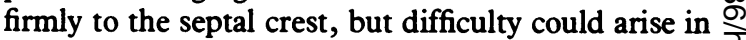
determining whether there was a small gap between them floored by the bare ventricular septal crest (that $t$ is a common orifice) or whether they were in con- iv tinuity (that is partitioned).

Ventricular size depends on the degree and level of

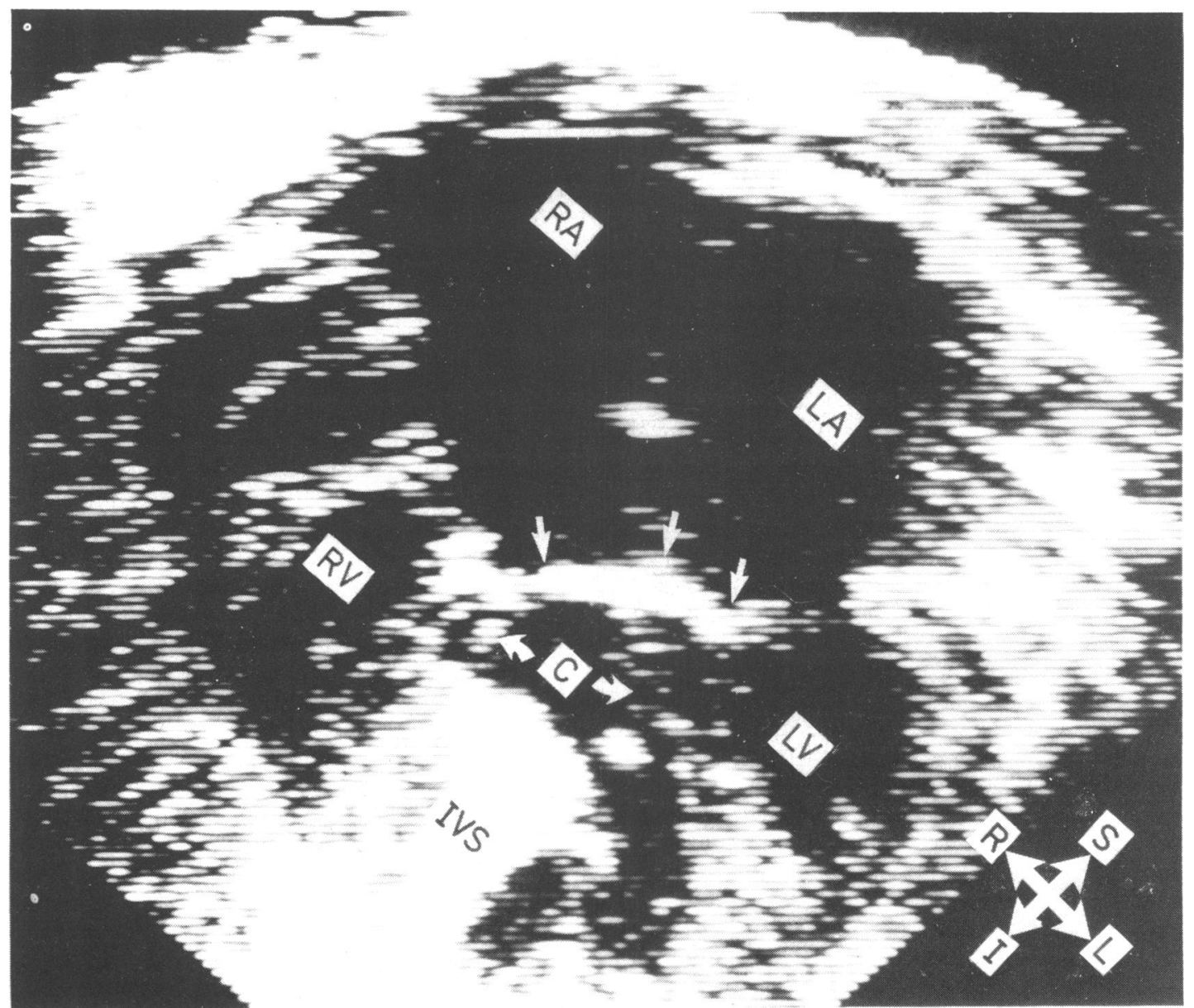

Fig. 8 An apical four chamber cut in a patient with a common atrioventricular orifice where the chordae from the anterior bridging leaflet, indicated by the arrows, are attached to the right side of the interventricular septum. C, chordae; IVS, interventricular septum. For remaining abbreviations see Fig. 1. 


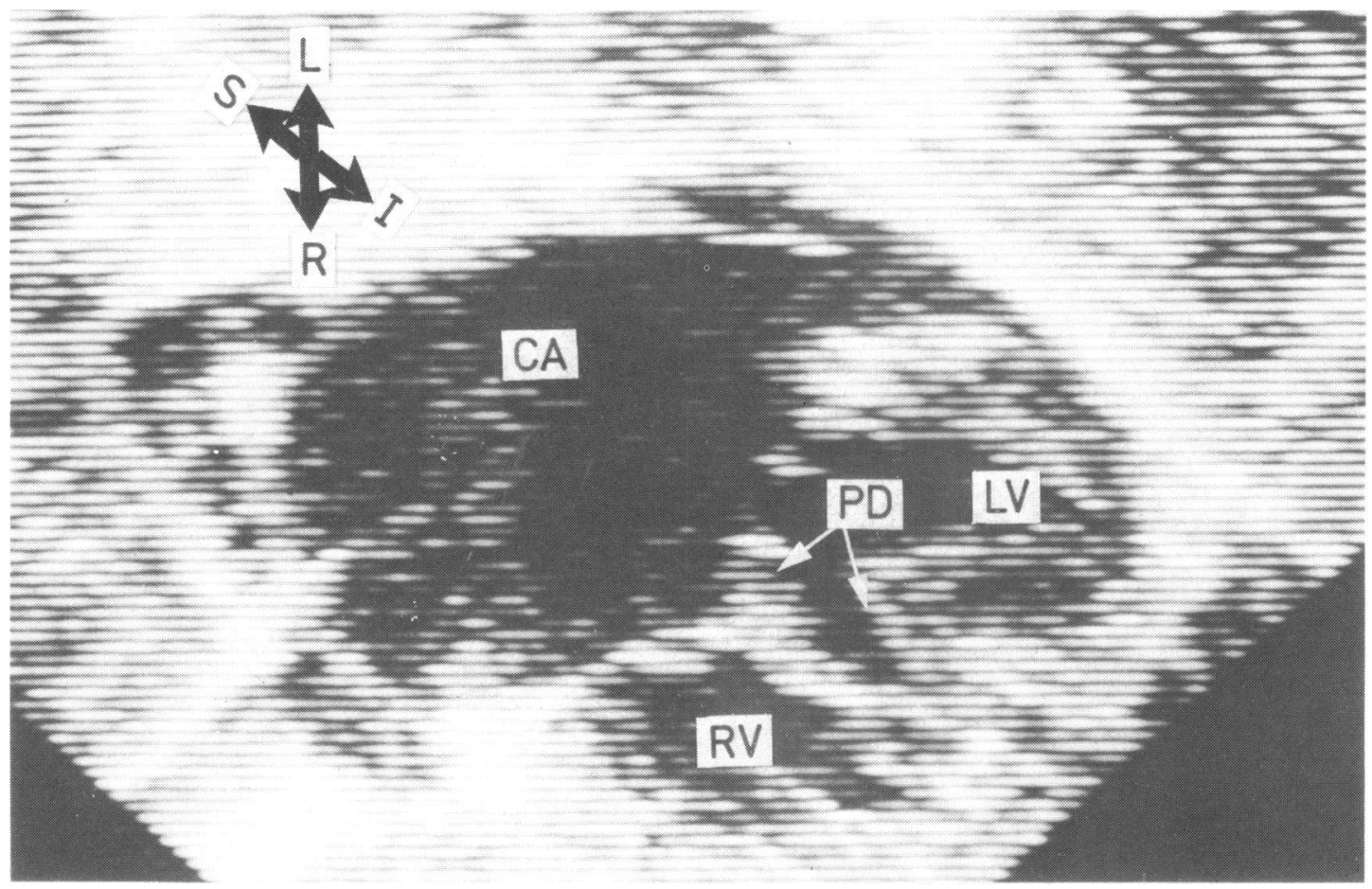

Fig. 9 A subcostal four chamber cut with a posterior ventricular septal defect. Note the defect beneath the posterior bridging leaflet indicated by the arrows. PD, posterior defect. For remaining abbreviations see Figs. 1 and 2.

shunting, as well as atrioventricular incompetence. ${ }^{19-21}$ Our echocardiographic observations, however, support in qualitative fashion the original pathological observation of Bharati and Lev ${ }^{10}$ that hearts exist in which the degree of right or left ventricular dominance cannot readily be explained on haemodynamic grounds (Fig. 9). Five of the patients described had this pattern of ventricular dominance. The distinction between this entity and univentricular hearts with common atrioventricular orifice has been discussed in detail elsewhere. ${ }^{7}$ In brief, we believe that the normal alignment of the atrial and ventricular septa is preserved in hearts with ventricular dominance and lost in univentricular hearts, though this is a subject requiring more detailed correlation between anatomical and echocardiographic findings.

From the echocardiographic point of view, what then are the features common to all atrioventricular septal defects? In all but a few cases either an ostium primum defect or common atrium was present. Independent of the type of defect, the level of leaflet tissue on either side of the septum is the same, reflecting the absence of the muscular atrioventricular septum. In the majority of cases, independent of whether they have a partitioned or non-partitioned orifice, the left sided atrioventricular valve has a tri-leaflet appearance, ${ }^{22}$ but with the division between the two components of the bridging leaflets unsupported by a papillary muscle. It is this division which is usually termed the "cleft", being readily recognised in the short axis section "pointing" towards the interventricular septum. This "cleft" is different from the isolated cleft seen in those with a normal anterior or aortic mitral valve leaflet.

With the advent of such precise non-invasive information regarding the anterior bridging leaflet and its attachments plus the presence or absence of an anterior defect and other associated anomalies, one may question the need for angiocardiography in cases where the anatomy is clear. The combination of clinical assessment together with pulsed Doppler demonstration of left and/or right atrial flow patterns probably provides adequate information about the degree of mitral regurgitation.

Until a non-invasive technique is developed which can reliably determine pulmonary artery pressure or vascular resistance, cardiac catheterisation will remain essential in older patients in whom pulmonary vascular disease is suspected. In infants in intractable heart failure, however, the decision to operate is based upon 

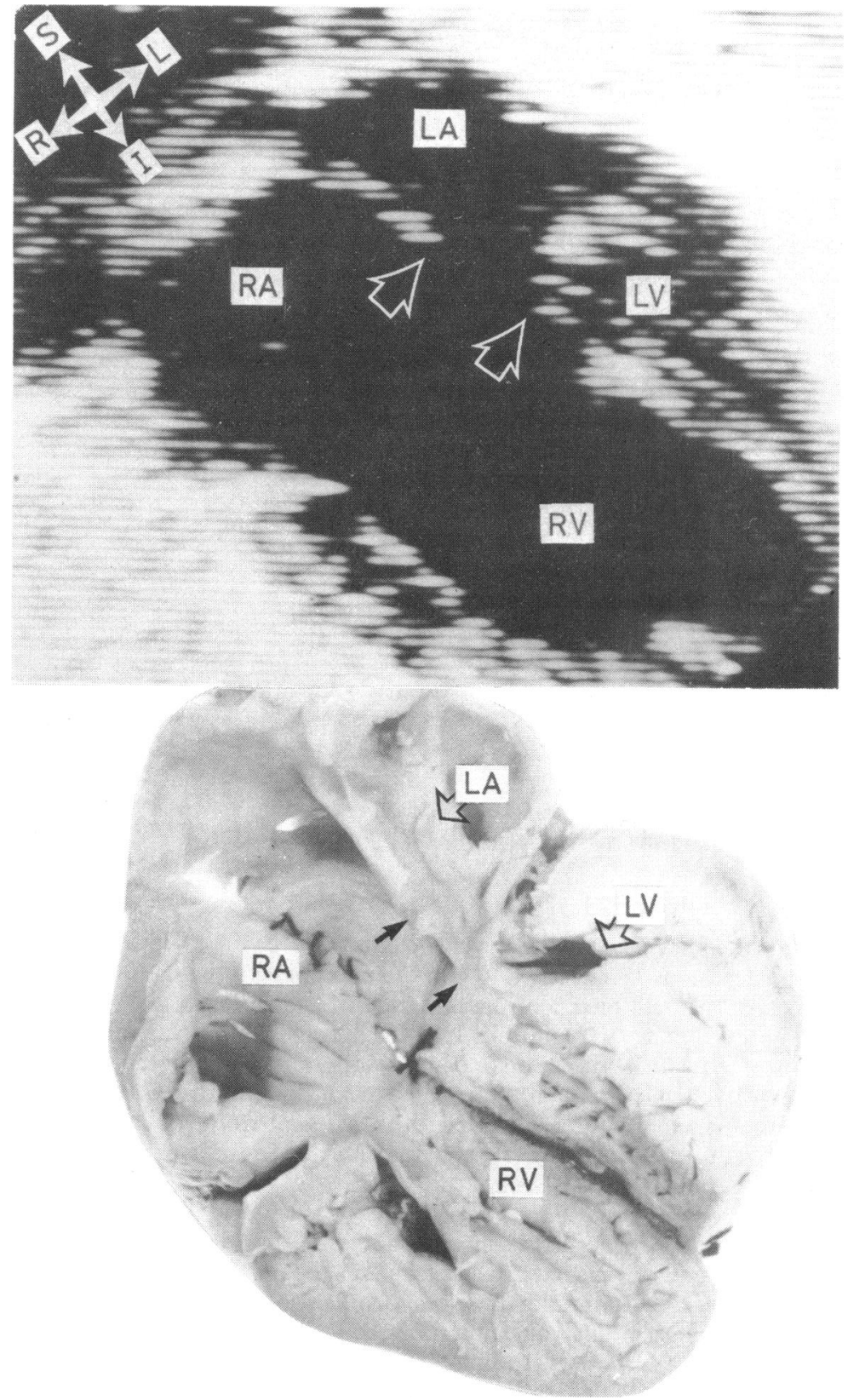

Fig. 10 The upper panel is an apical four chamber cut in a case with an atrioventricular septal defect and a dominant right ventricle. The ostium primum defect is indicated by the large arrows. The lower panel is a specimen from a case with an atrioventricular septal defect and a dominant right ventricle. The ostium primum defect is indicated by the arrows. See Fig. 1 for abbreviations. their clinical status, and we have operated on a number of such patients without prior cardiac catheterisation.

It therefore appears that in depth morphological information of the type of atrioventricular septal defect can be obtained with this technique and that visualisation of a significant ventricular component under the anterior bridging leaflet is possible in all $\stackrel{O}{E}$ cases. Defects under the posterior bridging leaflet can $\mathbb{D}$ be visualised in most cases. If, however, the ventricular communication exists in between thickened short chordae, then visualisation of $\frac{\pi}{\mathbb{D}}$ either anterior or posterior defect is unlikely by this technique. 
JFS was a British Heart Foundation Junior Research Fellow. RHA and FJM are supported by the British Heart Foundation and, respectively, the Joseph Levy and Vandervell Foundations.

\section{References}

1 Hagler DJ, Tajik AJ, Seward JB, Mair DD, Ritter DG. Real-time wide-angle sector echocardiography: atrioventricular canal defects. Circulation 1979; 59: 140-50.

2 Rastelli GC, Kirklin JW, Titus JL. Anatomic observations on complete form of persistent common atrioventricular canal with special reference to atrioventricular valves. Mayo Clin Proc 1966; 41: 296-308.

3 Berger TJ, Kirklin JW, Blackstone EH, Pacifico AD, Kouchoukos NT. Primary repair of complete atrioventricular canal in patients less than 2 years old. $A m \mathcal{F}$ Cardiol 1978; 41: 906-13.

4 Bharati S, Lev M, McAllister HA Jr, Kirklin JW. Surgical anatomy of the atrioventricular valve in the intermediate type of common atrioventricular orifice. $\mathcal{F}$ Thorac Cardiovasc Surg 1980; 79: 884-9.

5 Piccoli GP, Gerlis LM, Wilkinson JL, Lozsadi K, Macartney FJ, Anderson RH. Morphology and classification of atrioventricular defects. Br Heart $\mathcal{F}$ 1979; 42: 621-32.

6 Piccoli GP, Wilkinson JL, Macartney FJ, Gerlis LM, Anderson RH. Morphology and classification of complete atrioventricular defects. Br Heart $\mathcal{F}$ 1979; 42: 6339.

7 Smallhorn JF, Tommasini G, Macartney FJ. Twodimensional echocardiographic assessment of common atrioventricular valves in univentricular hearts. $\mathrm{Br}$ Heart f 1981; 46: 30-4.

8 Tajik AJ, Seward JB, Hagler DJ, Mair DD, Lie JT. Two-dimensional real-time ultrasonic imaging of the heart and great vessels. Technique, image orientation, structure identification, and validation. Mayo Clin Proc 1978; 53: 271-303.

9 Macartney FJ, Rees PG, Daly K, et al. Angiocardiographic appearances of atrioventricular defects with particular reference to distinction of ostium primum atrial septal defect from common atrioventricular orifice. $\mathrm{Br}$ Heart f 1979; 42: 640-56.

10-Bharati S, Lev $M$. The spectrum of common atrioventricular orifice (canal). Am Hean $\mathcal{F}$ 1973; 86: 553-61.
11 Sutherland GR, van Mill GJ, Anderson RH, Hunter S. Sub-xiphoid echocardiography - a new approach to the diagnosis and differentiation of atrioventricular defects. Eur Heart f 1980; 1: 45-54.

12 Bass JL, Bessinger FB Jr, Lawrence C. Echocardiographic differentiation of partial and complete atrioventricular canal. Circulation 1978; 57: 1144-50.

13 Van Mierop LHS, Alley RD, Kausel HW, Stranahan A. The anatomy and embryology of endocardial cushion defects. F Thorac Cardiovasc Surg 1962; 43: 71-83.

14 Blieden LC, Randall PA, Castaneda AR, Lucas RV, Edwards JE. The "goose neck" of the endocardial cushion defect: anatomic basis. Chest 1974; 65: 13-17.

15 Somerville J, Jefferson $\mathrm{K}$. Left ventricular angiocardiography in atrioventricular defects. Br Heart $\mathcal{F}$ 1968; 30: 446-57.

16 Brandt PWT, Clarkson PM, Neutze JM, Barratt-Boyes BG. Left ventricular cineangiocardiography in endocardial cushion defect. (Persistent common atrioventricular canal.) Australas Radiol 1972; 16: 367-76.

17 Wakai CS, Edwards JE. Developmental and pathologic considerations in persistent common atrioventricular canal. Proc Staff Meetings Mayo Clin 1956; 31: 487-500.

18 Bedord DE, Sellors TH, Somerville W, Belcher JR, Besterman EMM. Atrial septal defect and its surgical treatment. Lancet 1957; i: 1255-61.

19 Thanopoulos BD, Fisher EA, DuBrow IW, Hastreiter AR. Right and left ventricular volume characteristics in common atrioventricular canal. Circulation 1978; 57: 991-5.

20 Culpepper W, Kolff J, Lin C-Y, et al. Complete common atrioventricular canal in infancy - surgical repair and postoperative hemodynamics. Circulation 1978; 58: $550-8$.

21 Jarmakani JM, George B, Wheller J. Ventricular volume characteristics in infants and children with endocardial cushion defects. Circulation 1978; 58: 153-7.

22 Carpentier A. Surgical anatomy and management of the mitral component of atrioventricular canal defects. In: Anderson RH, Shinebourne EA, eds. Paediatric cardiology 1977. Edinburgh: Churchill Livingstone, 1978: 477-86.

Requests for reprints to Professor F J Macartney, The Hospital for Sick Children, Great Ormond Street, London WCIN 3JN. 